PREVENTION \& REHABILITATION: ORIGINAL RESEARCH STUDY

\title{
A patellar bandage improves mobility but not static balance in elderly female fallers
}

\author{
Marcos Eduardo Scheicher a, b, c, *, Ligia Cristiane Santos Fonseca d, e, \\ Tiago Buso Bortolloto ${ }^{\text {a, }}$, Isabela Feitosa de Carvalho ${ }^{\text {a, c }}$ \\ a Department of Physical Therapy and Occupational Therapy, São Paulo State University (UNESP), Marília, São Paulo, Brazil \\ b Postgraduate Program in Human Development and Technologies, São Paulo State University (UNESP), Rio Claro, São Paulo, Brazil \\ c 737 Hygino Muzzi Filho Avenue, 17.525-900 Marília, São Paulo, Brazil \\ d Department of Rehabilitation \& Prevention Engineering, Helmholtz Institute, RWTH Aachen University, Germany \\ e Thomas Schmitz-Rode, Pauwelsstraße 20, D-52074 Aachen, Germany
}

Keywords:

Aging

Accidental falls

Postural balance

Proprioception

Compression bandages

\begin{abstract}
A B S T R A C T
Background: The deterioration in the somatosensory and motor systems observed with increasing age can cause balance problems. Studies have shown that the use of infrapatellar bandages can enhance proprioception and improve postural balance.

Aims: To evaluate the effect of an infrapatellar bandage on static balance and mobility in elderly female fallers and non-fallers.

Methods: Forty older women (20 fallers and 20 non-fallers) were evaluated. Mobility (Timed Up and Go test) and balance (force platform) were measured in the presence and absence of additional sensory information (elastic infrapatellar bandage).

Results: Mobility differed in fallers $(\mathrm{p}=0.0001)$, but not in non-fallers $(\mathrm{p}=0.27)$, when the patellar bandage was applied. Additional sensory information did not improve static balance in either group $(\mathrm{p}>0.05)$, but a trend towards improvement was observed in fallers.

Conclusion: Additional sensory input from an infrapatellar bandage improves mobility but not bipedal stance in elderly fallers.
\end{abstract}

๑ 2017 Elsevier Ltd. All rights reserved.

\section{Introduction}

Falls are common among older people and result in their need for health care, thus representing a serious public health problem in this population (World Health Organization, 2016). Falls are a leading problem in general practice because of their high incidence, association with many risk factors, and considerable postfall morbidity and mortality (Tinetti et al., 1988; Campbell et al., 1990; O'Loughlin et al., 1993; Nevitt et al., 1989). One-third of people aged 65 years and over fall one or more times a year. In communitydwelling older people, the cumulative incidence of falls ranges from 25 to 40\% (Stalenhoef et al., 1997).

\footnotetext{
* Corresponding author. 737 Hygino Muzzi Filho Avenue, 17.525-900 Marília, São Paulo, Brazil.

E-mail addresses: mscheicher@marilia.unesp.br (M.E. Scheicher), fonseca@ame. rwth-aachen.de (L.C.S. Fonseca), tigobuso@hotmail.com (T.B. Bortolloto), isabelafeitosa.fisio@gmail.com (I.F. de Carvalho).
}

The deterioration in the function of somatosensory and motor systems observed with increasing age can cause balance problems (Stalenhoef et al., 2000; Lord et al., 1991). Our sense of body position and movement irrespective of vision (i.e., proprioception) relies on muscle spindle feedback and is vital for performing motor acts. The proprioceptive system provides the central nervous system with information concerning joint angles and changes in these angles detected by muscle spindles, Golgi tendon organs and joint afferents (Riemann and Lephart, 2002). Over the last decade, studies have investigated the effect of somatosensory information on stance control using the technique of smooth touch on a rigid surface (Holden et al., 1994; Jeka and Lackner, 1994, 1995). In those studies, adult subjects exhibited a significant reduction in body oscillation when they stood up and touched the tip of the index finger on a rigid and stationary surface. Since the strength applied to the surface was not sufficient to provide significant mechanical support (Holden et al., 1994), the improvement in stance control was suggested to be the result of the additional sensory stimulus provided by the finger touching a stationary surface (Jeka and 
Lackner, 1994, 1995). These studies indicate that sensory information and motor activity are correlated in terms of maintaining the body at a given position and that additional sensory information can be used continuously, causing a reduction in body oscillation.

Studies have shown that the use of infrapatellar bandages can enhance proprioception in young athletes with anterior cruciate ligament injury (Barrett et al., 1991; Birmingham et al., 1998; Bonfim and Barela, 2007). Felicio et al. (2014) evaluated the effect of a patellar bandage on the postural control of subjects with and without patellofemoral pain syndrome and concluded that additional sensory input from a patellar bandage increases proprioceptive feedback, which may be related to improved postural control in subjects with this syndrome. According to Bonfim et al. (2009), the application of additional sources of sensory information can be decisive for patients who have some impairment in the acquisition of sensory stimuli (such as the elderly). In this case, the addition of sensory stimuli may offer a unique opportunity to improve motor performance.

Few studies have investigated the relationship between balance and additional sensory stimulation in elderly fallers and non-fallers and whether these subjects can benefit from this stimulus for improving postural balance and mobility. A review evaluating the effects of shoes and other ankle or foot appliances on postural balance in the elderly found only six studies that explored the topic and no conclusion could be drawn due to methodological differences (Hijmans et al., 2007). Hijmans et al. (2009) found that ankle compression was associated with improvement of joint position sense, but not of bipedal stance, in older people. The objective of this study was to evaluate the effect of a patellar bandage on static postural balance and mobility in elderly female fallers and nonfallers.

\section{Materials and methods}

\subsection{Participants}

In a cross-sectional study, postural control and mobility were assessed in a convenience sample of 40 older female volunteers under two different conditions, with and without a patellar bandage.

The participants were allocated to two different groups (see Table 1), a faller and a non-faller group. All volunteers enrolled in the study were selected in the same way from primary health units, health centers, community centers, and geriatric clinics. The following subjects were excluded: subjects with neurological or musculoskeletal disorders or pain that interfered with their daily activities, subjects with lower extremity joint replacement, subjects with orthostatic postural hypotension, subjects with abnormal scores on the Mini-Mental State Examination according to educational level (Brucki et al., 2003) and subjscts that indicated the use of psychoactive or vasoactive medications at the time of testing. A fall was defined as the unintentional displacement of the body to a level lower than the starting position, with the inability of correction in a timely manner.

Table 1

Characteristics of fallers and non-fallers participating in the study.

\begin{tabular}{llll}
\hline & Fallers $(\mathrm{n}=20)$ & Non-fallers $(\mathrm{n}=20)$ & p value \\
& Mean $(\mathrm{SD})$ & Mean $(\mathrm{SD})$ & \\
Age (years) & $69.5 \pm 5.2$ & $69.8 \pm 4.3$ & 0.92 \\
MMSE & $25.9 \pm 3.3$ & $27.05 \pm 2.7$ & 0.30 \\
Number of medications & $3.2 \pm 1.7$ & $3.6 \pm 2.5$ & 0.57 \\
Number of falls & $2.7 \pm 2.8$ & - & $<0.0001$ \\
Body mass index $\left(\mathrm{kg} / \mathrm{m}^{2}\right)$ & $31.4 \pm 7.6$ & $28.2 \pm 5.6$ & 0.10 \\
\hline
\end{tabular}

MMSE: Mini-Mental State Examination.
The anthropometric characteristics of the subjects are shown in Table 1 (see Table 1). All participants answered questionnaires regarding their personal data, history of falling (place, number, and sequelae), and number of medications.

Written informed consent was obtained from all patients before enrollment. The study was approved by the Research Ethics Committee of the Faculty of Philosophy and Sciences, Universidade Estadual Paulista (UNESP), Marília, São Paulo, Brazil, and was conducted in accordance with Resolution No. 196/96 of the National Health Council (Protocol 0428/2012).

\subsection{Procedure}

All assessments were performed by the same person, a trained physiotherapist. Static balance and mobility were evaluated in the taped and untaped conditions. The taped condition consisted of the placement of a subpatellar bandage strap (Salvapé ${ }^{\circledR}$ ) made of 2.0$\mathrm{cm}$ wide elastic band with an anterior Microfoam pad and a Velcro tape for closure (see Fig. 1), placed on each participant according to manufacturer instructions. The order of the untaped or taped condition was allocated randomly. For randomization, a number was assigned to the taped (1) and untaped condition (2) and each participant was allocated by drawing lots to the group that would begin to be evaluated with or without a patellar bandage. The subjects were allowed to rest for $60 \mathrm{~s}$ between trials ( 3 attempts) and for $15 \mathrm{~min}$ between test situations (taped/untaped). The design of the study is illustrated in Fig. 2 (see Fig. 2).

\subsection{Mobility}

Mobility was evaluated by the Timed Up and Go test (TUG). The TUG has been recommended as a simple fall risk screening tool, primarily to identify people warranting more detailed assessment of mobility (Schoene et al., 2013; American Geriatrics Society and British Geriatrics Society, 2011). The test measures the time (in seconds) necessary for a person to rise from a chair with armrests, walk $3 \mathrm{~m}$ at a comfortable walking speed, turn, return to the chair, and sit down (Podsiadlo and Richardson, 1991). Poor TUG performance has been associated with low muscle strength, poor balance, slow gait speed, fear of falling, and physical inactivity (Podsiadlo and Richardson, 1991; Takahashi et al., 2006). The test was performed twice in the untaped and taped condition, first for familiarization and then for time recording.

\subsection{Static balance}

Postural stability was assessed by the same rater in the same

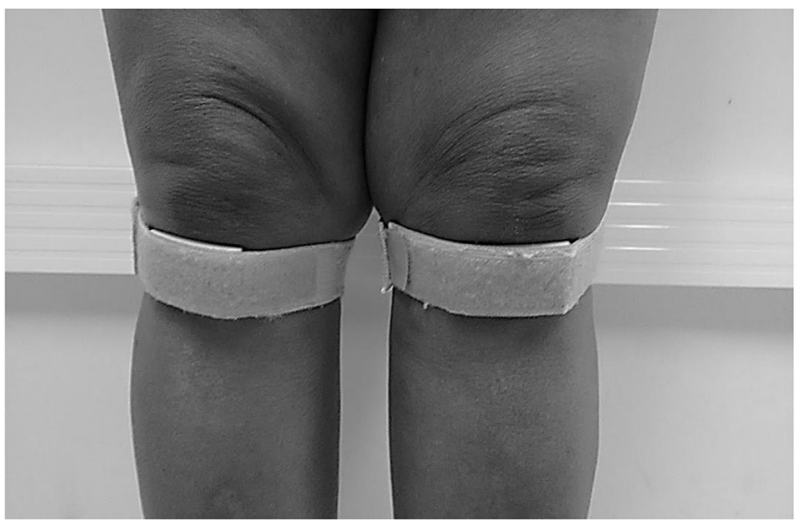

Fig. 1. Infrapatellar bandage. 


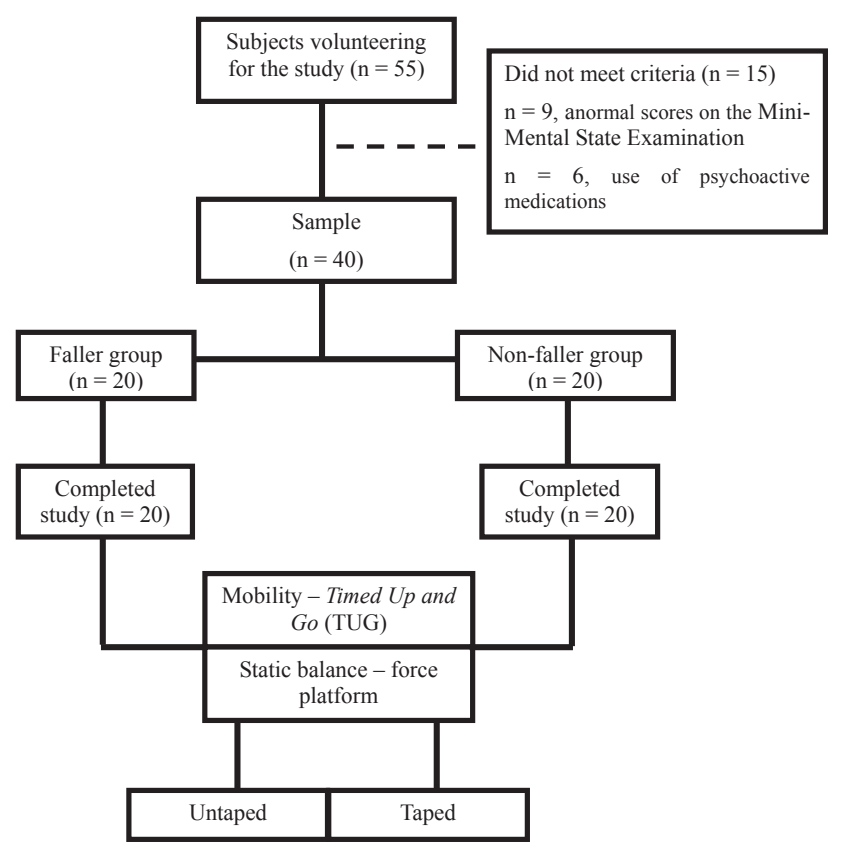

Fig. 2. Procedures of data collection.

laboratory environment. Center of pressure (COP) data were obtained using an $\mathrm{AMTI}^{\circledR}$ force platform (AccuSway Dual Top, Watertown, MA, USA). Data were sampled at $100 \mathrm{~Hz}$ and transformed to obtain COP values. The subjects stood quietly while barefoot, looking straight ahead, feet at 50\% hip-to-hip distance, and arms at their sides. The subjects completed three consecutive balance trials in the untaped and in the taped condition.

The force platform provided data on force and moment in the vertical and horizontal axis, which were used to calculate the COP in anteroposterior and mediolateral directions. Three attempts were made and each attempt was recorded for $30 \mathrm{~s}$. The data provided by the force platform were assessed using a function written in MATLAB language, which processes the data regarding the force applied to the platform: Fx (force applied to the platform in the anteroposterior direction), Fy (force applied in the mediolateral direction), and $\mathrm{Fz}$ (force applied in the vertical direction).

\subsection{Statistical analysis}

Comparisons were made between groups and between the taped and untaped conditions. Linear mixed effects models were used for analysis of the data, in which the participants were the random effects and the different conditions (with and without a patellar bandage) were the fixed effects. Differences were considered significant when $\mathrm{p} \leq 0.05$. All statistical analyses were performed using the Action Stat ${ }^{\circledR}$ program.

The mixed effect model assumes that the residual between the predicted and observed values has a normal distribution with a zero mean and constant variance.

\section{Results}

\subsection{Mobility}

The TUG time in the absence of compression was $14.98 \pm 2.9 \mathrm{~s}$ in the faller group and $11.89 \pm 2.8 \mathrm{~s}$ in the non-faller group $(\mathrm{p}=0.001)$, showing greater changes in mobility in elderly fallers compared to elderly non-fallers. Fig. 3 (see Fig. 3) shows a significant reduction

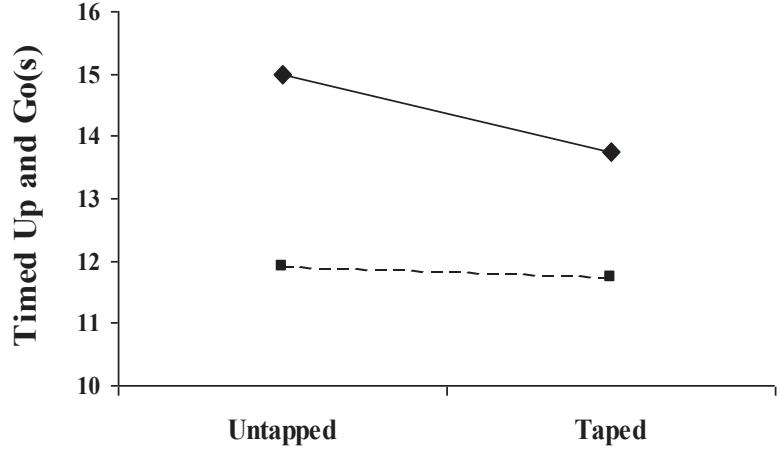

Fig. 3. Comparison of TUG time in fallers $(n=20$, continuous line; $p=0.0001$ ) and non-fallers ( $\mathrm{n}=20$, dashed line; $\mathrm{p}=0.27$ ) between the untaped and taped conditions.

in TUG time after application of the patellar bandage in the faller group ( $p=0.0001$ ), while no difference was observed in the nonfaller group $(\mathrm{p}=0.27)$.

\subsection{Stance control}

No significant differences in stance balance were observed in the faller or non-faller group when compression was applied (see Table 2). There was a decrease in some of the variables, but the difference was not significant.

\section{Discussion}

The aging process is related to decreasing balance control, a situation that may lead to falls. The somatosensory system plays an important role in balance control and age-related declines in somatosensory function have been implicated in the incidence of falls (Qiu et al., 2012). The identification of alternative low-cost treatments that decrease the risk of falling is a challenge for researchers. The aim of this study was to evaluate the effect of a patellar bandage on static postural balance and mobility in elderly female fallers and non-fallers.

The results showed that the faller group benefited from the inclusion of additional sensory information in mobility, with the observation of a significant decrease in TUG time (see Fig. 3). In a prospective study, Verghese et al. (2009) found that each $10 \mathrm{~cm} / \mathrm{s}$ decrease in gait speed resulted in a $7 \%$ increase in the risk of falls. Thus, a decrease in TUG time (as shown in our study) indicates an increase in gait speed, better balance, improved functional mobility and, consequently, a lower risk of falling.

Although our results did not show significant improvement in postural control parameters for static balance with additional sensory input to the anterior knee in faller group, some variables decreased, indicating a trend towards improvement. The improvement in TUG performance of elderly fallers may have been due to increased proprioceptive feedback and changes in postural adjustments arising from the additional sensory input given by the patellar bandage, improving sensory information quality and proprioceptive responses. This, in turn, would increase activity in the motor cortex, suggesting a possible influence of additional sensory information on motor control (Callaghan, 2011). Edin (2001) showed that skin mechanoreceptors provide high-fidelity information about knee movement and that the stabilizing effects of bandages in large joints such as the knee can be attributed to changes in somatosensory inflow from the skin to the central nervous system.

In the non-faller group, the patellar bandage did not elicit significant changes in body sway or mobility. These individuals 
Table 2

Variables of static balance.

\begin{tabular}{|c|c|c|c|c|c|c|}
\hline Group & Variable & Untaped & $\mathrm{CI}$ & Taped & $\mathrm{CI}$ & Difference \\
\hline \multirow[t]{7}{*}{ Fallers } & Total displacement $(\mathrm{cm})$ & $24.03(12.78)$ & $(18.04-30.01)$ & $22.12(11.5)$ & $(16.73-27.50)$ & -1.91 \\
\hline & Displacement X $(\mathrm{cm})$ & $21.10(7.9)$ & $(17.40-24.79)$ & $20.00(8.0)$ & $(16.25-23.74)$ & -1.10 \\
\hline & Displacement Y (cm) & $7.70(2.9)$ & $(6.34-9.05)$ & $7.20(3.2)$ & $(5.70-8.69)$ & -0.50 \\
\hline & Total mean speed $(\mathrm{cm} / \mathrm{s})$ & $15.70(5.96)$ & $(12.91-18.48)$ & $15.71(6.5)$ & $(12.66-18.75)$ & 0.01 \\
\hline & Mean speed X $(\mathrm{cm} / \mathrm{s})$ & $13.91(5.48)$ & $(11.34-16.47)$ & $13.84(6.0)$ & $(11.03-16.64)$ & -0.07 \\
\hline & Mean speed Y (cm/s) & $5.05(2.05)$ & $(4.09-6.00)$ & $5.07(2.53)$ & $(3.88-6.25)$ & 0.02 \\
\hline & Area $\left(\mathrm{cm}^{2}\right)$ & $15.40(8.5)$ & $(11.42-19.37)$ & $14.40(9.2)$ & $(10.09-18.70)$ & -1.00 \\
\hline \multirow[t]{7}{*}{ Non-fallers } & Total displacement $(\mathrm{cm})$ & 19.95(13.2) & $(13.77-26.12)$ & $20.47(13.89)$ & $(13.96-26.97)$ & 0.52 \\
\hline & Displacement X $(\mathrm{cm})$ & $17.90(8.7)$ & $(13.82-21.97)$ & $17.80(8.0)$ & $(14.05-21.54)$ & -0.10 \\
\hline & Displacement Y (cm) & $6.50(3.3)$ & $(4.95-8.04)$ & $6.40(2.9)$ & $(5.04-7.75)$ & -0.10 \\
\hline & Total mean speed $(\mathrm{cm} / \mathrm{s})$ & $13.44(6.5)$ & $(10.39-16.48)$ & $13.50(6.58)$ & $(10.42-16.57)$ & 0.06 \\
\hline & Mean speed X $(\mathrm{cm} / \mathrm{s})$ & $11.90(5.98)$ & $(9.10-14.69)$ & $12.04(5.4)$ & $(9.51-14.56)$ & 0.14 \\
\hline & Mean speed Y (cm/s) & $4.66(2.22)$ & $(3.62-5.69)$ & $4.37(2.0)$ & $(3.43-5.30)$ & -0.29 \\
\hline & Area $\left(\mathrm{cm}^{2}\right)$ & $14.85(21.1)$ & $(4.97-24.72)$ & $11.32(9.0)$ & $(7.10-15.53)$ & -3.53 \\
\hline
\end{tabular}

Values are the mean (standard deviation). CI: Confidence interval.

probably have little proprioceptive deficits. Thus, the additional sensory information provided by the tape had no beneficial effects on static balance or mobility in these participants.

Some studies have reported improvement in postural balance using patellar bandages in different clinical situations (Felicio et al., 2014; Bonfim et al., 2009). However, in the study of Birmingham et al. (2001), postural control was not significantly affected by the use of a brace during the stable surface test.

The patellar bandage is a low-cost appliance that can reduce the risk of falls. Nevertheless, further studies are needed to establish the mechanisms of action of the additional sensory input provided by the patellar bandage in elderly fallers. Some questions need to be answered including whether or not the stimulus is local; whether the additional stimulus is superficial or reaches the lower layers such as muscles, joint capsules, tendons and ligaments; whether changes occur in muscle recruitment, and especially whether there are long-term effects.

Our study has some limitations. First, the position of the subjects' feet on the force platform (enlarged base) may have facilitated the task. Ideally, the subjects should have been evaluated in a postural condition that generates instability (semi-tandem position), thus increasing the difficulty for the postural control system. Second, although the strap was placed on each participant according to manufacturer instructions, the pressure exerted may have differed between individuals, with a consequent difference in outcome. Third, only one type of patellar strap was used in this study. Since the design of patellar straps varies between brands, the results obtained in this study might not be generalizable to other types of straps.

\section{Conclusions}

Our findings indicate that additional sensory input from a patellar bandage was associated with improved mobility in elderly fallers. However, no significant improvement in static balance was observed. On the other hand, application of the patellar bandage did not improve mobility or static balance in elderly non-fallers.

\section{Ethical approval}

This study was approved by the local Ethics Committee on research involving humans (CEP 428/2012) and was conducted in accordance with ethical standards.

\section{Conflict of interest}

None.

\section{Acknowledgments}

This project was funded by Fundação de Amparo à Pesquisa do Estado de São Paulo (FAPESP; Grant 2011/07548-6).

\section{References}

American Geriatrics Society and British Geriatrics Society, 2011. Summary of the updated American geriatrics society/British geriatrics society clinical practice guideline for prevention of falls in older persons. J. Am. Geriatrics Soc. 59 (1), 148-157.

Barrett, D.S., Cobb, A.G., Bentley, G., 1991. Joint proprioception in normal, osteoarthritic and replaced knees. J. Bone Jt. Surg. 73 (1), 53-56.

Birmingham, T.B., Kramer, J.F., Inglis, J.T., et al., 1998. Effect of a neoprene knee sleeve on knee joint position sense during sitting open kinetic chain and supine closed kinetic chain tests. Am. J. Sports Med. 26, 562-566.

Birmingham, T.B., Kramer, J.F., Kirkley, A., Inglis, J.T., Spaulding, S.J. Vandervoort, A.A., 2001. Knee bracing for medial compartment osteoarthritis: effects on proprioception and postural control. Rheumatology 40 (30), $285-289$.

Bonfim, T.R., Barela, J.A., 2007. Efeito da manipulação da informação sensorial na propriocepção e no controle postural. Fisioter. em Mov. 20, 107-117.

Bonfim, T.R., Grossi, D.B., Paccola, C.A.J., Barela, J.A., 2009. Efeito de informação sensorial adicional na propriocepção e equilíbrio de indivíduos com lesão do LCA. Acta Ortopédica Bras. 17 (5), 291-296.

Brucki, S.M.D., Nitrini, R., Caramelli, P., Bertolucci, P.H.F., Okamoto, I.H., 2003. Sugestões para o uso do mini-exame do estado mental no Brasil. Arq. NeuroPsiquiatria 61, 777-781.

Callaghan, M.J., 2011. What does proprioception testing tell us about patellofemoral pain? Man. Ther. 16 (1), 46-47.

Campbell, A.J., Borrie, M.J., Spears, G.F., Jackson, S.L., Brown, J.S., Fitzgerald, J.L., 1990 Circumstances and consequences of falls experienced by a community population 70 years and over during a prospective study. Age Ageing 19 (2), 136-141.

Edin, B., 2001. Cutaneous afferents provide information about knee joint movements in humans. J. Physiol. 531 (Pt 1), 289-297.

Felicio, L.R., Masullo, L.C., Saad, M.C., Bevilaqua-Grossi, D., 2014. The effect of a patellar bandage on the postural control of individuals with patellofemoral pain syndrome. J. Phys. Ther. Sci. 26(30, 461-464.

Hijmans, J.M., Geertzen, J.H.B., Dijkstra, P.U., Postema, K., 2007. A systematic review of the effects of shoes and other ankle or foot appliances on balance in older people and people with peripheral nervous system disorders. Gait Posture 25 (2), 316-323.

Hijmans, J.M., Zijlstra, W., Geertzen, J.H.B., Hof, A.L., Postema, K., 2009. Foot and ankle compression improves joint position sense but not bipedal stance in older people. Gait Posture 29 (2), 322-325.

Holden, M., Ventura, J., Lackner, J.R., 1994. Stabilization of posture by precision contact of the index finger. J. Vestib. Res. 4 (4), 285-301.

Jeka, J.J., Lackner, J.R., 1994. Fingertip contact influences human postural control. Exp. Brain Res. 79 (2), 495-502.

Jeka, J.J., Lackner, J.R., 1995. The role of haptic cues from rough and slippery surfaces in human postural control. Exp. Brain Res. 103, 267-276.

Lord, S.R., Clark, R.D., Webster, I.W., 1991. Postural stability and associated physiological factors in a population of aged persons. J. Gerontol. 46 (3), M69-M76.

Nevitt, M.C., Cummings, S.R., Kidd, S., Black, D., 1989. Risk factors for recurrent nonsyncopal falls. J. Am. Med. Assoc. 261 (18), 2663.

O'Loughlin, J.L., Robitaille, Y., Boivin, J.F., Suissa, S., 1993. Incidence of and risk factors for falls and injurious falls among the community-dwelling elderly. Am. J. Epidemiol. 137, 342-354.

Podsiadlo, D., Richardson, S., 1991. The Timed 'Up \& Go': a test of basic functional 
mobility for frail elderly persons. J. Am. Geriatrics Soc. 39 (2), 142-148.

Qiu, F., Cole, M.H., Davids, K.W., Hennig, E.M., Silburn, P.A., Netscher, H., Kerr, G.K., 2012. Enhanced somatosensory information decreases postural sway in older people. Gait Posture 35 (4), 630-635.

Riemann, B.L., Lephart, S.M., 2002. The sensorimotor system, part I: the physiologic basis of functional joint stability. J. Athl. Train. 37 (1), 71-79.

Schoene, D., Wu, S.M., Mikolaizak, A.S., Menant, J.C., Smith, S.T., Delbaere, K., Lord, S.R., 2013. Discriminative ability and predictive validity of the timed up and go test in identifying older people who fall: systematic review and metaanalysis. J. Am. Geriatrics Soc. 61 (2), 202-208.

Stalenhoef, P.A., Crebolder, H.F.J.M., Knottnerus, J.A., Van Der Horst, F.G.E.M., 1997. Incidence, risk factors and consequences of falls among elderly subjects living in the community A criteria-based analysis. Eur. J. Public Health 7 (3), 328-334.

Stalenhoef, P.A., Diederiks, J.P., Knottnerus, J.A., de Witte, L.P., Crebolder, H.F., 2000.
The construction of a patient record-based risk model for recurrent falls among elderly people living in the community. Fam. Pract. 17 (6), 490-496.

Takahashi, T., Ishida, K., Yamamoto, H., Takata, J., Nishinaga, M., Doi, Y. Yamamoto, H., 2006. Modification of the functional reach test: analysis of lateral and anterior functional reach in community-dwelling older people. Archives Gerontol. Geriatrics 42 (2), 167-173.

Tinetti, M.E., Speechley, M., Ginter, S.F., 1988. Risk factors for falls among elderly persons living in the community. N. Engl. J. Med. 319 (26), 1701-1707.

Verghese, J., Holtzer, R., Lipton, R.B., Wang, C., 2009. Quantitative gait markers and incident fall risk in older adults. J. Gerontol. Ser. A Biol. Sci. Med. Sci. 64 (8), 896-901.

World Health Organization, 2016. Falls. Fact sheet No. 344. http://www.who.int/ mediacentre/factsheets/fs344/en/. Accessed August 242016. 